\title{
Relational integrativity of prime-target pairs moderates congruity effects in evaluative priming
}

\author{
Max Ihmels $^{1} \cdot$ Peter Freytag $^{1} \cdot$ Klaus Fiedler $^{1} \cdot$ Theodore Alexopoulos $^{2}$
}

Published online: 21 December 2015

(C) Psychonomic Society, Inc. 2015

\begin{abstract}
In evaluative priming, positive or negative primes facilitate reactions to targets that share the same valence. While this effect is commonly explained as reflecting invariant structures in semantic long-term memory or in the sensorimotor system, the present research highlights the role of integrativity in evaluative priming. Integrativity refers to the ease of integrating two concepts into a new meaningful compound representation. In extended material tests using paired comparisons from two pools of positive and negative words, we show that evaluative congruity is highly correlated with integrativity. Therefore, in most priming studies, congruity and integrativity are strongly confounded. When both aspects are disentangled by manipulating congruity and integrativity orthogonally, three priming experiments show that evaluativepriming effects were confined to integrative prime-target pairs. No facilitation of prime-congruent targets was obtained for non-integrative stimuli. These findings are discussed from a broader perspective on priming conceived as flexible, context-dependent, and serving a generative adaptation function.
\end{abstract}

Keywords Evaluative priming · Affective priming · Relational integration $\cdot$ Integrativity $\cdot$ Semantic priming

Electronic supplementary material The online version of this article (doi:10.3758/s13421-015-0581-8) contains supplementary material, which is available to authorized users.

Max Ihmels

max.ihmels@psychologie.uni-heidelberg.de

1 Department of Social Psychology, University of Heidelberg, Hauptstr. 47-51, D-69117 Heidelberg, Germany

2 Department of Psychology, Université Paris Descartes, Paris, France

\section{Introduction}

In the evaluative priming (EP) paradigm (Fazio, Sanbonmatsu, Powell, \& Kardes, 1986; Herring et al., 2013), target stimuli have to be classified as fast as possible as either positive or negative. The typical EP effect is that on congruent trials, when targets are preceded by primes of the same valence, evaluative decisions are faster and, given a sizeable error rate, also more accurate than on incongruent trials, when prime and target are of opposite valence.

$\mathrm{EP}$ is a special instance of category priming. For EP effects, it is sufficient that prime and target fall into the same valence category, regardless of other aspects of semantic similarity and denotative meaning. For instance, "sunshine" and "altruistic" are semantically quite distant from each other, just as "murder" and "boring", but the two pairs share a single semantic attribute, namely positive or negative valence, respectively. By focussing on valence as the most preeminent attribute (Osgood, Suci, \& Tannenbaum, 1957) while disregarding many other attributes that affect the distance of stimulus meaning in semantic space, EP is a special instance of semantic priming. EP divides the world into two very broad semantic categories, contrasting everything we like, agree with, or approve against everything we dislike, disagree with, or disapprove, abstracting from other semantic attributes.

Thus, the domain of EP is enormous. Every valenced prime is supposed to have the potential to facilitate responses to virtually all evaluatively congruent targets. There is no restriction in the domain of the basic congruity principle, as evident in the assumption that EP is generally applicable for implicit measurement of virtually all attitudes (Fazio, 2001; Wittenbrink \& Schwarz 2007). Without any restriction of the valence domain, it is assumed that positive or negative attitude objects have the potential, when used as a prime in an EP task, to facilitate responses to valence-congruent targets. The degree of facilitation over multiple valenced targets is used as a 
quantitative (implicit) measure of the attitude toward the prime.

To be sure, this universal assumption holds at the functional level of analysis; it only says that EP applies valence-congruent stimulus pairs, regardless of the cognitive process (spreading activation or response facilitation) that accounts for the congruity effect at the mechanistic level. In any case, the term "evaluative priming" refers to a priming effect that is only constrained by valence, not by other more restrictive semantic attributes.

It may not be too surprising that this very broad notion of EP is not supported by a growing body of evidence pointing to manifold moderators and limiting conditions such as: Stimulus onset asynchrony [SOA] (De Houwer, Hermans, \& Eelen, 1998), prime extremity (Glaser \& Banaji 1999), or stimulus context (Klauer, Rossnagel, \& Musch, 1997). The present research constitutes an attempt to understand the various limiting conditions and to restrict the domain of EP in a theoretically reasonable way by implementing the concept of relational integrativity (Estes \& Jones, 2009). Integrativity refers to the extent to which a concept (e.g., a prime) can be combined with a second concept (i.e., a target), thereby generating a distinct new compound meaning. As evaluative congruency and integrativity are typically confounded in EP - in that integrative pairs are much more likely congruent than incongruent - the aim of the present research is to demonstrate that EP is at least partially due to integrativity. Across three experiments, we show that EP effects are largely confined to integrative stimulus pairs.

\section{Theoretical accounts of evaluative priming (EP)}

Classical accounts Consistent with the initial claim of EP as a universal and automatic effect, classical theoretical accounts refer to invariant structural causes, attributing EP either to associative proximity of congruent stimuli in semantic long-term memory or to enhanced compatibility or matching of motor (submotor or motivational-affective) responses elicited by congruent stimuli (Fazio et al., 1986; Hermans, Van den Broeck, \& Eelen, 1998; Klinger, Burton \& Pitts, 2000; Scherer \& Lambert, 2009). ${ }^{1}$

Note that both long-term associative memory and response compatibility imply invariant structural advantages for congruent prime-target pairs. As it is impossible to organize associative structures such that incongruent relations are closer to each other than congruent relations, spreading activation theories predict a robust and pervasive congruity effect. The notion of response compatibility is also bound to a universal congruity effect; it invariantly predicts that submotor impulses elicited by the prime

\footnotetext{
${ }^{1}$ This is the case of still another account, the affective matching model (Klauer \& Stern, 1992; Wentura, 2000), which describes a post-lexical mechanism where stimuli are compared for their evaluative consistency. An evaluative consistency facilitates affirmative responses whereas an evaluative inconsistency facilitates negative responses. Thus, this model predicts a congruity advantage specifically in tasks requiring affirmative/ negative responses.
}

facilitate a congruent (rather than an incongruent) response to the target. In either case, to explain incongruity effects (Fiedler, Bluemke, \& Unkelbach, 2011; Glaser \& Banaji, 1999; Herring et al., 2013), one has to postulate additional processes, such as post-lexical consistency checks or meta-cognitive correction.

Such auxiliary ad-hoc accounts of absent or reversed EP effects remain dissatisfactory, however, as long as there is no cogent evidence for an isolated correction process. Consider the following list of strong moderators. The congruity advantage has been shown to disappear or to be reversed (a) when the time interval between prime onset and target onset (SOA) is relatively long (Hermans, Spruyt, \& Eelen, 2003); (b) when stimulus words are common rather than rare (Chan, Ybarra \& Schwarz, 2006); (c) when participants are in negative mood states (Storbeck \& Clore, 2008); (d) when most prime-target transitions in the stimulus list are incongruent (Fiedler et al., 2011; Klauer, Rossnagel, \& Musch, 1997; Spruyt, Hermans, De Houwer, Vandromme, \& Eelen, 2007); (e) when participants actively respond to primes rather than only to targets (Fiedler et al., 2011); (f) when uncertainty about the location of a target is reduced (Musch \& Klauer, 2001), or (g) when attention is oriented towards nonaffective stimulus features (Spruyt, De Houwer, Hermans, \& Eelen, 2007; Spruyt, De Houwer, \& Hermans, 2009). Why should the mind attenuate or correct for an upcoming prime influence exactly under these conditions? Why should it be adaptive to cease following an environmental signal when SOA lasts a second, when a frequently used stimulus word appears, when in a negative mood, when reacting to the prime, when the stimulus list includes few congruent pairs, when the prime location is clearly defined, or when non-affective features are the focus of attention?

Alternative accounts Rather than reflecting corrections of fixed associations in long-term memory or motor pathways, all these priming failures and reversals may reflect flexible processes in working memory (Estes \& Jones, 2009; Fiedler et al., 2011; Ratcliff \& McKoon, 1988). From this perspective, priming conceived as a malleable adaptive process is sensitive to flexible online inferences about task structure and stimulus context. Primes may be discounted and functionally separated from targets, rather than assimilated, when the time interval (SOA) is long, when extra reactions or stimuli separate primes from targets, or when negative mood inhibits assimilative mental operations (Fiedler \& Hütter, 2013; Storbeck \& Clore, 2008). This rationale is also well in line with the psychophysical account by Klauer, Teige-Mocigemba, and Spruyt (2009), which assumes that activation of positive and negative valence is accumulated in separate nodes or counters. In order to evaluate a stimulus, the decision-maker accesses the recent change of these counters within a specific time window. Depending on the dynamic adjustments of this evaluation window used to judge a target, this can lead to assimilation or contrast effects. Assimilation occurs when primes are included in the evaluation window and contrast 
effects occur when primes have contributed to the initial counter states but no longer drive changes in these counters inside the evaluation window.

Such adjustments and inferences are also tailored to the current stimulus context. For example, given a list context within which most primes precede targets of opposite valence, adaptive inferences may facilitate responses to incongruent targets. Just as the utilization of perceptual cues is open to vicarious functioning (Brunswik, 1952), allowing for relearning of specific cue functions as in Kohler's (1962) famous mirror-glass experiments, target evaluation may be conceived as a constructive process that allows for flexible prime utilization. Depending on whether prime-target pairs are encoded as integral or separable experiences, target evaluations may be biased (or not) toward primes.

Integrative priming One intriguing variant of such internally generated prime-target construal was recently pointed out by Estes and Jones (2009) for semantic priming. Drawing on Gagné's (2000) notion of relational integration, these authors demonstrated that noun pairs (such as "horse" - "doctor") that bear little semantic overlap but solicit creative inferences of a new emergent compound ("a horse doctor") lead to strong integrative priming effects. Participants showed faster responses in lexical decision tasks when the target could be more easily integrated with the prime. From a constructivist perspective, these findings make perfect sense because the very propensity of a noun pair to generate a compound is incompatible with the separation of the prime from the target. It rather facilitates a generative process of prime-target integration and assimilation (Alexopoulos, Fiedler, \& Freytag, 2012).

\section{Integrativity as a key to understanding EP}

The aim of the present research is to study the role of integrative-priming in the EP paradigm. Previous research has already suggested that EP entails generative post-lexical inferences, like for example combining primes and targets into the interrogative construction "is (prime) (target)?" (e.g., "is death wise?"; Klauer \& Stern, 1992; Wentura, 1999), but these precursors did not provide a direct test of the contribution of integrativity to this kind of plausibility check.

We believe that integrativity plays an even stronger role in EP than in semantic priming, because evaluative congruity places weaker constraints on prime-target pairs than semantic relatedness. Primes may only facilitate the evaluation of congruent targets when both can be integrated into a compound, rather than evaluative responses to all congruent targets. Thus, EP effects should be observed for integrative pairs like "shower - pleasant" but not for equally congruent but nonintegrative pairs like "candle - funny." If so, integrativity would greatly constrain the theoretical meaning of EP, reducing the phenomenon from a generalized congruity effect to a more restrictive advantage for congruent integrative stimulus pairs. This would be also in line with the notion of a "fan effect" (Anderson \& Bower, 1973), which implies that the impact of a single prime is unlikely to carry over to a gigantic fan of a thousand other valenced targets.

With respect to Maki and Buchanan's (2008) distinction of three types of association measures - semantic feature overlap, co-occurrence rates in stimulus environments and likelihood of generating a target stimulus from a cue in an association test - integrativity can be conceived as a relational function of the latter type. It reflects the readiness to generate an associative link between selected pairs of a cue (prime) and a target. Such integrative associations between selected pairs (but not between all valence-congruent pairs) are relatively independent of the other two types of association, based on feature overlap (i.e., the semantic proximity) and co-occurrence rate (in the empirical world). Although integrativity can itself be conceived as a specific semantic function, it is clearly distinct from distance in terms of feature overlap or co-occurrence rate (for a related discussion, see Estes \& Jones, 2009). Thus, the semantic features of "shower" and "pleasant" show little overlap, and they rarely co-occur in text corpora. However, they have the semantic propensity to construe a meaningful and vividly experienced compound: "pleasant shower."

Although integrativity is conceptually close to other relational constructs, it is by no means redundant. There are several empirical findings supporting the relative independence of integrativity and association measures. Recent work by Mather, Jones, and Estes (2014) showed that integrative priming effects are independent from similarity or co-occurrence. In two experiments they obtained robust integrative priming effects using a perceptual identification task (Experiment 1) and a Stroop color-naming task (Experiment 2) with wordpair stimuli (e.g., mushroom - soup) that were low in associative strength, similarity, or co-occurrence as indexed by various measures (association norms; similarity ratings; LSA cosines; Google hits). Thus, integrative priming can be empirically set apart from associative or semantic priming. Furthermore, in a systematic comparison of integrative, thematic (e.g., prescription - doctor), and taxonomic (e.g., nurse - doctor) relationships of word pairs taken from the Semantic Priming Project, Jones and Golonka (2012) reported a negative correlation between integrativity and taxonomic relatedness and no correlation between integrativity and thematic relatedness. These relations were further contrasted on additional measures of semantic richness (e.g., familiarity, similarity). It is noteworthy that integrativity was negatively correlated with feature similarity and measures of global cooccurrence but positively related to local co-occurrence and familiarity. Taken together, these findings support the idea that integrativity is a genuine and non-overlapping type of word pair relationship supporting a distinct type of priming based on a plausibility check (see Mather et al., 2014). 
Thus, the integrativity perspective on EP would appear to be functionally plausible, because the ease of forming an integrative prime-target compound (cf. Gagné, 2000) can be expected to support the priming process. It is only natural that target evaluation relies on a prime that easily merges with the target in the course of inference making. Such integration ease should facilitate fast responding to congruent stimulus pairs (since the correct response is the same as that which would be adequate for the prime) but not to incongruent pairs, when ease and incongruency are in conflict. In contrast, an absence of such integration ease should reduce priming effects.

The notion that EP increases with integrativity is also consistent with the repeated demonstration that EP disappears when prime and target are functionally separated, granting that separation is the opposite of integration. For instance, EP effects decrease or disappear when responses are solicited between prime and target (Fiedler et al., 2011), or when the SOA between prime and target is long (De Houwer et al., 1998).

Integrativity can also account for the conspicuous asymmetry of EP effects. When all four combinations of positive and negative prime valence and positive and negative target valence are considered, the congruity advantage is mostly due to positive-positive pairs (Burghardt \& Unkelbach, 2014; Fiedler et al., 2011; Unkelbach, Fiedler, Bayer, Stegmueller, \& Danner, 2008). Facilitation for negative-negative trials is either weak or fully absent. This asymmetry may reflect that positive-positive pairs tend to be more integrative than negative-negative pairs. Empirical support for this testable assumption would not only provide a viable account for asymmetric EP effects, it would also be in line with the heightened density and interconnectedness of positive memory representations (Unkelbach et al., 2008) and with the repeated finding that positive affective valence facilitates generative mental activities (Fiedler, Nickel, Asbeck, \& Pagel, 2003). Moreover, it would be consistent with the related observation that negative language is more precise and differentiated than positive language (Rozin, Berman, \& Royzman, 2010). And this precision of negative language might reduce its priming potential.

Although congruity and integrativity bear a strong ecologic correlation - integrative stimulus pairs are likely to share the same valence - it is possible to disentangle the two confounded variables. Both congruent pairs and incongruent stimulus pairs can be deliberately selected to be either integrative or non-integrative. Provided the integrativity of the word compounds can be shown to be independent of the valence of the composite words, which has to be partialled out, we can then test to what extent the typical EP effect (i.e., congruity, mostly for positive stimuli) is stronger for integrative than for non-integrative prime target pairs.

\section{Preview of research and predictions}

To test these considerations, we conducted three EP experiments varying integrativity in addition to prime valence and target valence. Both experiments employed the same task setting and procedure, but completely independent stimulus sets to enhance the generality of the integrativity effect. The aim was to test three ordered hypotheses: (1) In a large stimulus pool, congruent prime-target pairs are more integrative than incongruent pairs; (2) positive congruent pairs are more integrative than negative congruent pairs; and (3) EP effects are significantly reduced for low- compared to high-integrativity pairs.

\section{Experiment 1}

A pilot study served to select the stimulus materials for the main experiment, such that integrativity could be varied independently of evaluative congruity.

\section{Method}

\section{Materials}

Twenty students of Heidelberg University were recruited for a material testing study. Twenty positive and 20 negative nouns selected from the Berlin Affective Word List (Võ, Jacobs, \& Conrad, 2006), and 20 positive and 20 negative adjectives taken from Hager, Mecklenbräuker, Möller, and Westermann (1985) and Möller and Hager (1991) served as stimuli. ${ }^{2}$ Positive and negative stimuli were matched regarding evaluative extremity and word length. Each participant was presented with a random subset of 400 out of all $40 \times 40=1,600$ nounadjective pairs. Participants rated on 21-point scales the ease with which two concepts could be meaningfully combined. The scale endpoints were labelled "absolutely incompatible" and "absolutely compatible." For each stimulus pair, the noun was presented alone for 1,000 ms (top left of the screen center) before the adjective appeared (top right of the screen center). Another 1,000 ms later, the rating scale appeared. The next trial began after an inter-trial interval of 2,000 ms.

As expected, an item-based analysis showed the mean integrativity rating to be clearly higher for congruent $(M=$ $12.65, S D=4.64)$ than for incongruent pairs $(M=8.19, S D$ $=4.02), t(1598)=20.54, p<.001$. This finding supports the hypothesized relationship between integrativity and congruity

\footnotetext{
2 To circumvent grammatical intricacies of noun pairs in the German language, we opted for a type of combination frequently used in priming research, namely, noun adjective pairs; regarding relational integrativity, nouns and adjectives are typically related to each other based on a concept-has-property-relation (e.g., combining the noun/prime "day" with the adjective/target "cold" might create the meaningful representation such as "a cold day"). All stimuli and their ratings can be found in the Appendix.
} 
and naturally also shows up in a point biserial correlation (with congruity being dichotomous) of $r=.46, p<.001$.

Also as hypothesized, integrativity was asymmetrically more enhanced for positive congruent $(M=14.30, S D=$ 4.55) than for negative congruent $(M=10.99, S D=4.11)$ pairs, $t(798)=10.82, p<.001$, which tended in turn to be higher in integrativity than positive-negative pairs $(M=$ $8.55, S D=4.07), t(798)=8.44, p<.001$. Negative-positive pairs were even lower in integrativity $(M=7.82, S D=3.94)$, $t(798)=2.55, p=.01$, indicating that positive nouns are more easily linked syntagmatically to negative preceding adjectives than negative nouns to positive adjectives.

For the main study, eight pairs of primes $(\mathrm{P})$ and targets $(\mathrm{T})$ were selected for each combination of prime valence $(\mathrm{P}+$ and $\mathrm{P}-$ ), target valence ( $\mathrm{T}+$ and $\mathrm{T}-$ ), and integrativity (high and low), such that congruent and incongruent pairs were matched for integrativity. This resulted in a total of 64 word pairs such as: "shower - pleasant" $(\mathrm{P}+\mathrm{T}+$, high $)$, "nature - dirty" $(\mathrm{P}+\mathrm{T}-$, high), "gas - natural" ( $\mathrm{P}-\mathrm{T}+$, high), "ammunition - loud" ( $\mathrm{P}-$ $\mathrm{T}-$, high); "cocoa - attractive" ( $\mathrm{P}+\mathrm{T}+$, low), "book - loud" ( $\mathrm{P}+\mathrm{T}-$, low), "corpse - pleasant" ( $\mathrm{P}-\mathrm{T}+$, low), "ammunition bleak" (P-T-, low).

For the highly integrative pairs, the ratings of congruent and incongruent pairs, respectively, were $\mathrm{M}_{\mathrm{P}+\mathrm{T}+}=19.76$, $\mathrm{M}_{\mathrm{P}-\mathrm{T}-}=18.65$ and $\mathrm{M}_{\mathrm{P}+\mathrm{T}-}=17.54, \mathrm{M}_{\mathrm{P}-\mathrm{T}+}=16.31$. For lowintegrativity pairs, the corresponding means were $\mathrm{M}_{\mathrm{P}+\mathrm{T}^{+}}=$ $4.30, \mathrm{M}_{\mathrm{P}-\mathrm{T}-}=4.30$ for congruent and $\mathrm{M}_{\mathrm{P}+\mathrm{T}-}=3.20, \mathrm{M}_{\mathrm{P}-\mathrm{T}+}$ $=2.90$ for incongruent pairs. ${ }^{3}$

Using the norm data provided by Võ, Jacobs, and Conrad (2006), we also made sure that valence did not vary across integrativity conditions. Average evaluations of primes were nearly identical for high and low integrativity with $M_{\text {PosHigh }}=$ 1.39 versus $M_{\text {PosLow }}=1.43$ for positive primes and $M_{\mathrm{NegHigh}}=$ -1.54 versus $M_{\text {NegLow }}=-1.52$ for negative primes.

\section{Procedure of main experiment}

Thirty-four students of the University of Heidelberg participated in small groups of up to six. One participant was excluded for being an outlier regarding his error rate $(>$ third quartile $+1.5 *$ interquartile range). Participants were told that the purpose of the experiment was to measure the speed with which words can be classified as positive or negative. Each trial of an extended series would involve two words, of which the first appeared only briefly on the screen, whereas the second word would remain on-screen until participants had classified it as either positive or negative, using two response keys

\footnotetext{
${ }^{3}$ For stimuli high in integrativity, these slight differences are reflected in a main effect of prime valence, $F(1,28)=4.46, p=.04, \eta_{\mathrm{p}}{ }^{2}=.138$ and an interaction of prime valence $\mathrm{x}$ target valence, $F(1,28)=16.99, p<.001$, $\eta_{\mathrm{p}}{ }^{2}=.378$. For low-integrative stimuli, there is only a marginally significant interaction of prime valence $\times$ target valence, $F(1,28)=3.60, p=$ $.07, \eta_{\mathrm{p}}^{2}=.114$.
}

(i.e., "y" and "-", respectively, on a QWERTZ-German keyboard). Every trial started with a prime presented for $320 \mathrm{~ms}$, followed by a blank screen for $130 \mathrm{~ms}$ and the presentation of a target $(\mathrm{SOA}=450 \mathrm{~ms})$. Participants were asked to evaluate the target as fast as possible. As soon as it was classified as positive or negative, the target was erased. During a 2,000-ms inter-trial interval, the screen remained blank. A fixation-cross presented for 1,000 ms in the middle of the screen signalled the start of the next trial. Each word pair was presented twice, yielding 128 trials.

\section{Results and discussion}

Mean latencies for correctly classified targets were computed within participants for $\mathrm{P}+\mathrm{T}+, \mathrm{P}+\mathrm{T}-, \mathrm{P}-\mathrm{T}+$, and $\mathrm{P}-\mathrm{T}-$ trials . To reduce the influence of outlier responses, responses below $300 \mathrm{~ms}$ ( $0.3 \%$ of trials) and responses above $1,500 \mathrm{~ms}$ ( $3.6 \%$ of trials) were removed (for similar cut-off values, see Fockenberg, Koole, \& Semin, 2008; Hermans, De Houwer, \&, Eelen, 1994, 2001). The data were still skewed and therefore normalized by applying a log transformation prior to averaging. Although the statistical analyses were based on the log data, the descriptive statistics are presented in terms of the natural $\mathrm{ms}$ scale (i.e., anti$\log$ transformed summary statistics). Note that this $\log$ transformation did not moderate the results obtained in any experiment.

In a 2 (prime valence) $\times 2$ (target valence) $\times 2$ (integrativity) ANOVA, a typical congruity effect is evident in a prime valence $\times$ target valence interaction, $F(1,32)=5.48, p=.03, \eta_{\mathrm{p}}^{2}=.146$. The left part of Fig. 1 illustrates this interaction and shows that when pooling across integrative and non-integrative trials, the congruity advantage (faster reaction times for congruent trials) is more pronounced for positive-positive pairs than for negativenegative pairs. A target valence main effect, $F(1,32)=4.14, p=$ $.05, \eta_{\mathrm{p}}{ }^{2}=.115$, is suggestive of a congruity advantage for positive targets. A main effect of integrativity, $F(1,32)=4.58, p=$ $.04, \eta_{\mathrm{p}}{ }^{2}=.125$, is indicative of faster responses for pairs high in integrativity.

The moderating impact of integrativity on evaluative priming is manifested in a three-way prime valence $\times$ target valence $\times$ integrativity interaction, $F(1,32)=8.15, p<.001, \eta_{\mathrm{p}}{ }^{2}=.203$. Moreover, a significant prime valence $\times$ integrativity interaction, $F(1,32)=4.93, p=.03, \eta_{\mathrm{p}}^{2}=.134$, reflects an enhanced influence of integrativity on positive primes (cf. Fig. 1), consistent with the asymmetric concentration of EP on positive trials. ${ }^{4}$

\footnotetext{
${ }^{4}$ It should be noted that a standard ANOVA affords a conservative test of an asymmetric interaction that is mainly due to a facilitation effect for positive targets following positive primes. As a consequence, the strength of the basic congruity effect (i.e., the prime valence $\times$ target valence interaction) and of the higher-order interaction with integrativity is therefore underestimated; more appropriate contrast analyses would thus provide stronger interaction effects (Rosenthal \& Rosnow, 1985). To avoid the problem of defining a theoretically appropriate contrast, though, we rely here on a conservative ANOVA test.
} 


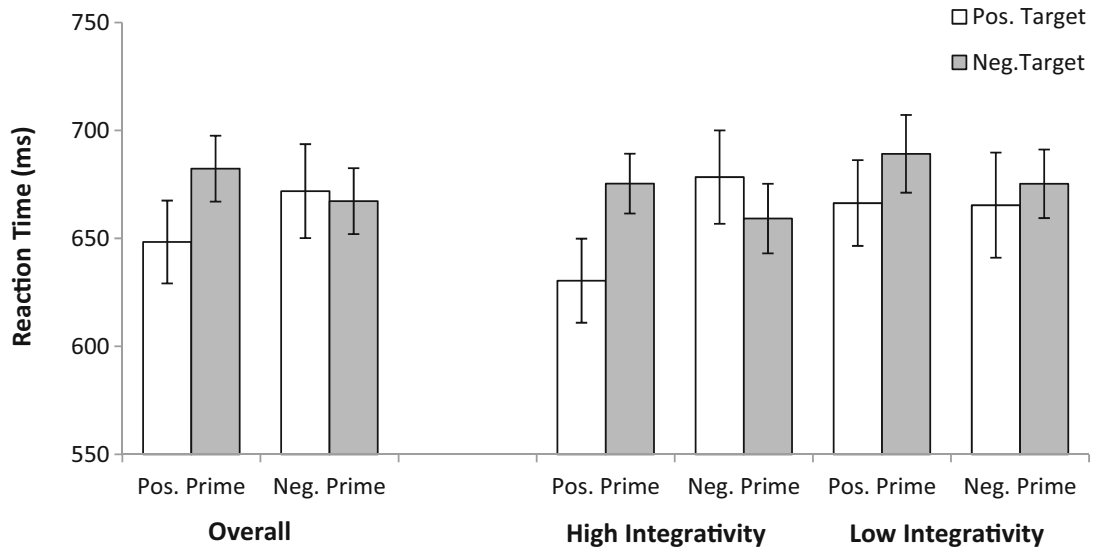

Fig. 1 Results from Experiment 1: mean reaction time (ms) as a function of prime valence, target valence, and integrativity. The left part shows the results pooled across all trials. The right part shows the results seperately for high- and low-integrativity trials. Error bars show standard errors

The right part of Fig. 1 gives insight into the nature of this three-way interaction. While there is a strong evaluative priming effect for stimuli high in integrativity, there is no congruity advantage for low-integrative stimuli. Two separate ANOVAs for high-integrative and low-integrative trials support this interpretation. As predicted, only for high-integrativity pairs did a significant prime valence $\times$ target valence interaction emerge indicating a clear-cut EP congruity effect, $F(1,32)=11.86$, $p<.01, \eta_{\mathrm{p}}{ }^{2}=.270$. In addition, a marginally significant effect of prime valence, $F(1,32)=3.27, p=.08, \eta_{\mathrm{p}}{ }^{2}=.093$, points to a congruity advantage for positive stimuli. For lowintegrativity pairs, the interaction effect was absent, $F<1$, and only a marginally significant effect for target valence, $F(1,32)=3.91, p=.06, \eta_{\mathrm{p}}{ }^{2}=.109$, emerged.

Given the use of fixed prime-target pairs, the findings are potentially sensitive to the language-as-fixed-effect fallacy (Clark, 1973). We therefore conducted an item analysis (F2 statistic) to assure generalizability to other stimuli. Importantly, when averaging across items instead of participants, the same critical three-way interaction emerged, $F(1,56)=4.04, p=.05$, $\eta_{\mathrm{p}}{ }^{2}=.067$. To qualify this three-way interaction, we again conducted separate ANOVAs for stimuli high and low in integrativity. For high-integrativity pairs, a significant prime valence $\times$ target valence emerged, $F(1,28)=9.43, p<.01, \eta_{\mathrm{p}}{ }^{2}=$ .252 . For low-integrativity pairs, this interaction was completely absent, $F<1$.

Altogether, these findings demonstrate that in a design that disentangles congruity and integrativity, there is no longer a uniform valence-based congruity effect, corroborating a strong version of our third hypothesis: EP effects were reduced (to non-existence) for low- compared to highintegrative word pairs. The robustness of this phenomenon is now tested in the next experiment using a completely new stimulus sample. To anticipate, a final experiment will then address the possibility that a lack of power or too long SOAs may have qualified the reported results.

\section{Experiment 2}

For the sake of generalizability, the second experiment constitutes a replication with a completely new set of prime and target stimuli.

\section{Method}

\section{Materials}

Thirty students of Heidelberg University participated in a similar pilot study to Experiment 1 . New sets of positive and negative nouns and adjectives (17 each) were selected (again controlling for evaluative extremity and word length) from Schwibbe, Räder, Schwibbe, Borchert, and GeikenPophanken (1981), yielding 1,156 noun-adjective pairs.

Again, mean integrativity ratings clearly distinguished between congruent $(M=13.31, S D=4.54)$ and incongruent pairs $(M=6.65, S D=4.20), t(1154)=25.91, p<.001$. The corresponding point biserial correlation between valence congruity (dichotomous) and mean integrativity amounts to $r=.61, p<$ .001. Enhanced integrativity was again clearly stronger for positive congruent pairs $(M=15.32, S D=3.86)$ than for negative congruent pairs $(M=11.30, S D=4.28), t(576)=11.88, p<$ .001 . For incongruent pairs, the low integrativity was more extreme when negative primes preceded positive targets $(M=$ $5.00, S D=3.35)$ than when positive primes preceded negative targets $(M=8.29, S D=4.32), t(576)=10.26, p<.001$.

Subsets of eight pairs were again selected for each combination of positive and negative primes and targets, separately for high and low integrativity, resulting in 64 different word pairs. Mean integrativity ratings of highly integrative pairs were again roughly equal for congruent, $M_{\mathrm{P}+\mathrm{T}+}=16.92, M_{\mathrm{P}-}$ $\mathrm{T}_{-}=15.20$, and incongruent pairs $M_{\mathrm{P}+\mathrm{T}-}=16.86, M_{\mathrm{P}-\mathrm{T}+}=$ 14.80. Likewise, for stimulus pairs low in integrativity, the mean ratings of congruent, $M_{\mathrm{P}+\mathrm{T}+}=6.73, M_{\mathrm{P}-\mathrm{T}-}=4.35$, and 


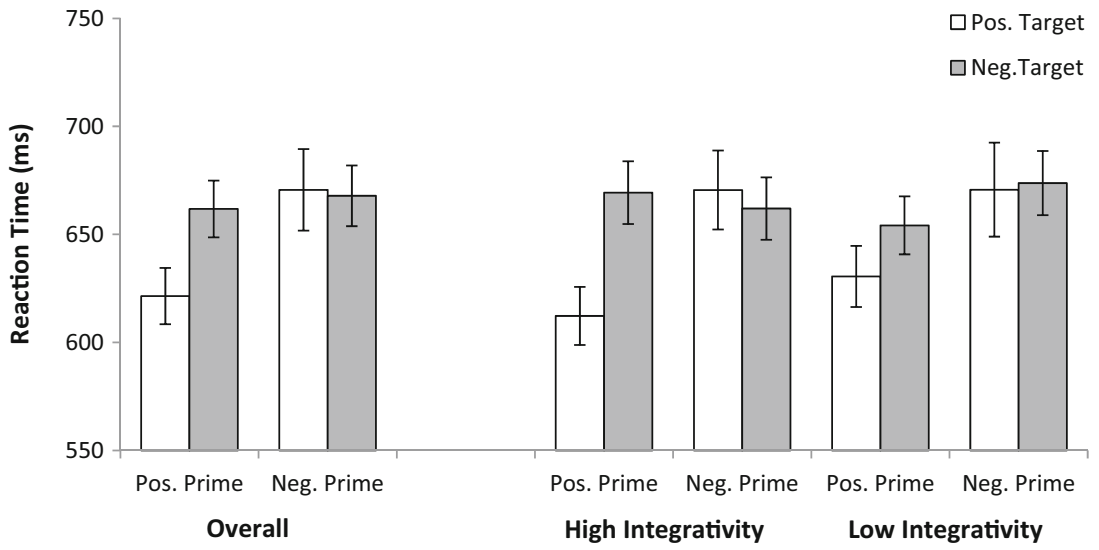

Fig. 2 Results from Experiment 2: mean reaction time (ms) as a function of prime valence, target valence, and integrativity. The left part shows the results pooled across high-integrativity and low-integrativity trials. The

right part shows the results seperately for high- and low-integrativity trials. Error bars indicate standard errors

incongruent pairs $M_{\mathrm{P}+\mathrm{T}-}=5.12, M_{\mathrm{P}-\mathrm{T}+}=4.42$, were comparable. $^{5}$

Using the norms provided by Schwibbe et al. (1981), we again ensured that valence did not vary across integrativity conditions. Average evaluations of primes were nearly identical for high and low integrativity with $M_{\text {PosHigh }}=5.08$ versus $M_{\text {PosLow }}=5.03$ for positive primes and $M_{\text {NegHigh }}=3.00$ versus $M_{\text {NegLow }}=2.97$ for negative primes.

\section{Main EP experiment}

Sixty students of Heidelberg University participated in the study. Four participants were excluded for being outliers with regards to their error rate (>third quartile $+1.5^{*}$ interquartile range). Except for the stimuli, the second experiment was in all details the same as the first EP experiment described above.

\section{Results and discussion}

The latency data were prepared in the same way as in Experiment $1(2.0 \%$ of trials were removed for being faster than $300 \mathrm{~ms}, 4.1 \%$ of trials were removed for being slower than 1,500 ms). Data were again still skewed and therefore normalized by applying a log transformation prior to averaging. A 2 (prime valence) $\times 2($ target valence $) \times 2$ (integrativity) ANOVA produced a similar pattern as in the first experiment. As evident from Fig. 2, however, the asymmetry of the EP effect was even more pronounced. Although a significant prime valence $\times$ target valence interaction, $F(1,56)=9.52, p$ $<.01, \eta_{\mathrm{p}}{ }^{2}=.144$, indicates that responses were faster for

\footnotetext{
${ }_{5}^{5}$ For high-integrative stimuli, the slight differences are reflected in a main effect for prime valence, $F(1,28)=5.28, p=.03, \eta_{\mathrm{p}}{ }^{2}=.159$. For lowintegrative stimuli, there is also a main effect of prime valence, $F(1,28)=$ $5.39, p=.03, \eta_{\mathrm{p}}^{2}=.162$.
}

congruent than for incongruent trials, this congruity advantage was exclusively due to facilitation on trials involving positive primes and positive targets (cf. Fig. 2). As mean latencies were generally faster for positive primes and for positive targets, there were marked main effects for prime valence, $F(1,56)$ $=22.06, p<.001, \eta_{\mathrm{p}}^{2}=.283$, and target valence, $F(1,56)=$ 7.82, $p<.01, \eta_{\mathrm{p}}{ }^{2}=.123$. Most importantly, the three-way prime valence $\times$ target valence $\times$ integrativity interaction was again significant, $F(1,56)=7.66, p<.01 \eta_{\mathrm{p}}^{2}=.120$.

A separate ANOVA for high-integrative stimuli yielded a prime-valence main effect, $F(1,56)=18.62, p<.001, \eta_{\mathrm{p}}{ }^{2}=$ .250 , a target-valence main effect, $F(1,56)=11.22, p<.01$, $\eta_{\mathrm{p}}{ }^{2}=.167$, and the critical prime valence $\times$ target valence interaction, $F(1,56)=18.32, p<.001, \eta_{\mathrm{p}}{ }^{2}=.247$. In contrast, when integrativity was low, only a prime valence main effect, $F(1,56)=10.07, p<.01, \eta_{\mathrm{p}}{ }^{2}=.152$, and a marginally significant target valence main effect were obtained, $F(1,56)=$ $3.02, p=.09, \eta_{\mathrm{p}}{ }^{2}=.051$. The prime valence $\times$ target valence interaction (the statistical test of congruity) was negligible, $F<1$.

To assure generalizability to other stimuli, we again conducted an item-analysis (F2 statistic). The three-way primevalence $\times$ target valence $\times$ integrativity interaction was marginally significant, $F(1,56)=3.53, p=.07, \eta_{\mathrm{p}}{ }^{2}=.059$. Two separate ANOVAs for stimuli high and low in integrativity revealed a marginally significant congruity effect in the form of a prime valence $\times$ target valence for stimuli high in integrativity, $F(1,28)=3.42, p=.08, \eta_{\mathrm{p}}{ }^{2}=.109$ but no interaction for stimuli low in integrativity, $F<1$.

Experiment 2 provided further evidence for the important role of integrativity in evaluative priming. Using a new set of stimuli, we again showed that when congruity and integrativity are disentangled, congruity effects are limited to high-integrative word pairs. However, one could argue that the SOA used in Experiments 1 and 2 was moderately long (i.e., $450 \mathrm{~ms}$ ). Such a time window might have allowed 
participants to engage in slow-acting, strategic processes which could somewhat strengthen the influence of integrativity. It is noteworthy that this argument is somewhat incompatible with Estes and Jones (2009) as well as Jones and Golonka (2012) who found that integrative priming is reduced or even eliminated, rather than enhanced, at longer SOAs. However, we wanted to rule out the possibility that our findings are simply due to a specific SOA value. We therefore ran a third experiment using a shorter SOA of $200 \mathrm{~ms}$ (Wentura \& Degner, 2010).

Moreover, since one of our arguments relies on the reduction or non-appearance of an effect (the EP in the low integrativity condition), it is crucial to conduct well-powered experiments. In contrast to the relatively small sample size in Experiment 1, Experiment 3 uses a larger sample to ensure satisfying statistical power. ${ }^{6}$

\section{Experiment 3}

The third experiment constitutes a replication using the stimulus set of Experiment 1, but with a larger sample and a shorter SOA (200 ms).

\section{Method}

\section{Materials}

The same materials were used as in Experiment 1.

\section{Main EP experiment}

Eighty-one students of the University of Heidelberg participated in the study. One participant was excluded for being an outlier with regard to his error rate ( $>$ third quartile $+1.5^{*}$ interquartile range). In most parts, this third experiment was a conceptual replication of the first two priming experiments. This time, however, we used a shorter SOA of $200 \mathrm{~ms}$. Every trial started with a fixation cross presented for $1,000 \mathrm{~ms}$, followed by a prime presented for $200 \mathrm{~ms}$, immediately overwritten by the target. As soon as the target was classified as either positive or

\footnotetext{
${ }^{6}$ We conducted a power analysis based on a meta-analysis by Herring et al. (2013) which samples many studies and therefore provides a more reliable estimation of the effect size than just our own experiments. For the evaluative decision task, Herring et al. (2013) computed an average effect size of $d=.45$. In a within-participants design, assuming an effect size of $d$ $=.45$, a significance level of $\alpha=.05$, a target power of $1-\beta=0.8$, and a two-tailed test, an appropriate sample size would be $N=41$. Experiment 1 $(\mathrm{N}=34)$ was slightly below this estimation. However, assuming the parameters above, this experiment still had a power of .72. Experiment $2(N=$ 60 ) provides a power of 92 . In Experiment 3, we thus decided to sample 81 participants and this gave us a power of .98 . This analysis suggests that there was sufficient power to detect an effect, given it is actually there.
}

negative, it was erased. After a 2,000-ms inter-trial interval, the next trial began. Each word pair was presented twice, yielding a total of 128 experimental trials.

\section{Results and discussion}

Latency data was again prepared in the same way as in Experiments 1 and $2(0.1 \%$ trials removed for being < $300 \mathrm{~ms}, 5.3 \%$ of trials removed for being $>1,500 \mathrm{~ms}$ ). ${ }^{7}$ Again, data were normalized by applying a $\log$ transformation.

A 2 (prime valence) $\times 2$ (target valence) $\times 2$ (integrativity) ANOVA produced a similar pattern to the first two experiments. Even though a significant prime valence $\times$ target valence interaction, $F(1,79)=34.53, p<.001, \eta_{\mathrm{p}}{ }^{2}=.304$, indicates faster responses for congruent trials, this congruity advantage was again exclusively due to facilitation on trials involving positive primes and positive targets (cf. Fig. 3). Main effects of prime valence, $F(1,79)=10.08, p<.01, \eta_{\mathrm{p}}^{2}=.113$, and target valence, $F(1,79)=28.02, p<.001, \eta_{\mathrm{p}}^{2}=.262$, indicated faster responses after positive primes and positive targets. This time, a main effect of integrativity also emerged, $F(1,79)=15.23, p<$ $.001, \eta_{\mathrm{p}}^{2}=.162$. Participants were generally faster in high- than low-integrative trials. There also was a marginal significant interaction of integrativity $\times$ prime valence, $F(1,79)=2.91$, $p=.09, \eta_{\mathrm{p}}{ }^{2}=.036$, pointing to more valence asymmetries when integrativity was high. Most critically, the three-way interaction of prime valence $\times$ target valence $\times$ integrativity was replicated, $F(1,79)=20.65, p<.001, \eta_{\mathrm{p}}^{2}=.207$.

A separate ANOVA for high-integrative stimuli yielded a prime-valence main effect, $F(1,79)=9.75, p<.01, \eta_{\mathrm{p}}{ }^{2}=.110$, a target-valence main effect, $F(1,79)=25.70, p<.001, \eta_{\mathrm{p}}{ }^{2}=$ .245 , and the prime valence $\times$ target valence interaction, $F(1$, 79) $=45.35, p<.001, \eta_{\mathrm{p}}{ }^{2}=.365$. In contrast, for low integrativity, only a main effect of target valence reflected faster reactions to positive than negative targets, $F(1,79)=$ $19.54, p<.001, \eta_{\mathrm{p}}{ }^{2}=.198$. The prime valence $\times$ target valence interaction (testing for congruity effects) did not reach significance, $F(1,79)=1.39, p=.24, \eta_{\mathrm{p}}{ }^{2}=.017$.

As in Experiments 1 and 2, we also conducted an item analysis (F2 statistic). The three-way interaction of prime valence $\times$ target valence $\times$ integrativity was again marginally significant, $F(1,56)=3.44, p=.07, \eta_{\mathrm{p}}^{2}=.058$. For stimuli high in integrativity, the congruity interaction of prime valence $\times$ target valence was highly significant, $F(1,28)=$ $8.14, p<.001, \eta_{\mathrm{p}}{ }^{2}=.225$, while it did not emerge for stimuli low in integrativity, $F<1$.

\footnotetext{
${ }^{7}$ Overall, participants in this experiment took generally longer to respond $(M=761 \mathrm{~ms})$ than in the previous two experiments $(M=667 \mathrm{~ms}$ in Exp. 1, $M=655 \mathrm{~ms}$ in Exp. 2), presumably due to the shortened SOA (200 ms). Thus, the upper cutoff value of $1,500 \mathrm{~ms}$ might be too strict and exclude some valuable data. However, using a more lenient criterion of 2,135 ms (i.e., mean latency $+2.5 S D \mathrm{~s} ; 1.8 \%$ of trials removed) leads to an identical pattern of results.
} 


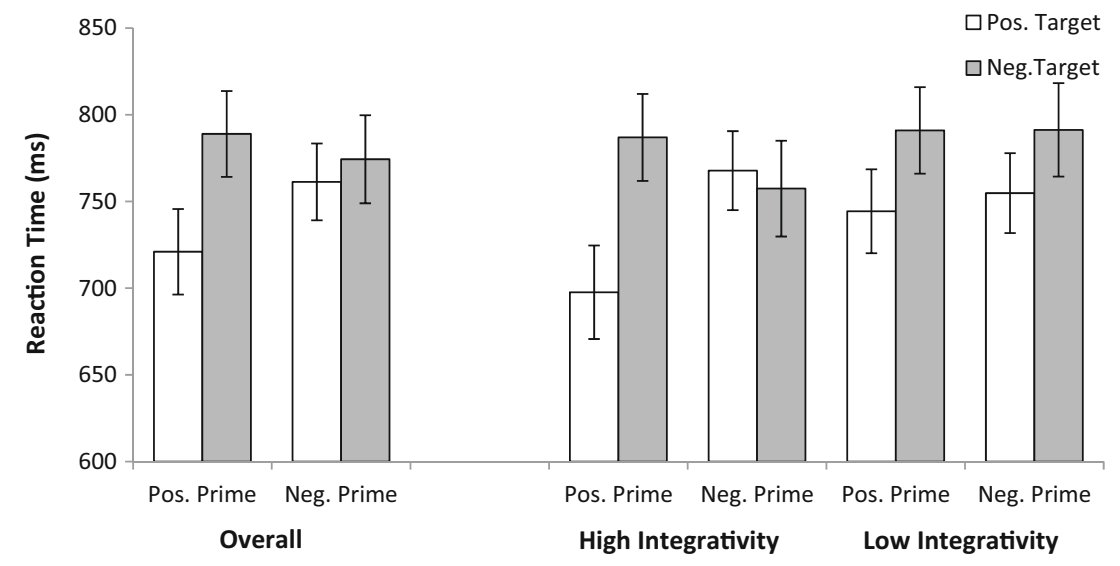

Fig. 3 Results from Experiment 3: mean reaction time (ms) as a function of prime valence, target valence, and integrativity. The left part shows the results pooled across high-integrativity and low-integrativity trials. The

right part shows the results seperately for high- and low-integrativity trials. Error bars indicate standard errors

\section{General discussion}

Overall, the findings obtained across all three experiments converged in a consistent pattern: An (asymmetric) congruity effect was only obtained under high integrativity. When integrativity was low, no congruity advantage was observed. The moderating role of integrativity was comparable across three evaluative priming experiments that varied the sets of verbal stimuli and SOAs. These clear-cut findings are perfectly in line with the integrative-priming results reported by Estes and Jones (2009) for semantic priming. They also challenge classic accounts of EP and provide support for the idea that relational integrativity of prime and target can facilitate target evaluation. The difference is that due to the nature of the EP task (classifying as positive or negative) our research was not about a main effect of integrativity, but about the potential of integrativity to potentiate evaluative congruency effects.

As predicted, then, the orthogonal variation of valence congruity and integrativity - two intrinsically confounded factors in EP experiments - lent support to integrativity as a crucial determinant of EP effects. Although the experiments yielded the typical (asymmetric) valence congruity effect that is commonly considered essential to EP, this was exclusively due to highintegrativity pairs. EP effects disappeared for low integrativity, although valence congruity was effectively manipulated in both subsets of prime-target pairs. It should be noted that it remains unclear whether the observed pattern of target reactions was due to facilitated processing of target words or a responsecompatibility of prime-target responses. Most likely, it is a consequence of both (Fazio, 2001; Klauer, Musch, \& Eder, 2005).

Because integrativity is normally confounded with valence congruity - most integrative pairs share the same valence - it is possible that apparent congruity effects in former EP studies may to an unknown degree reflect the impact of integrativity, which has never been controlled before. Future research will

have to test this possibility systematically, using both different verbal and non-verbal stimuli (e.g., images).

Although the present work does provide some evidence that these integrative priming effects are consistent over (relatively) short and moderate SOAs, looking at other presentation formats (subliminal durations; pictures instead of words) or paradigms (e.g., lexical decision or pronunciation tasks with an independent manipulation of congruity and integrativity) might also help gauging the scope of integrative priming effects. We do not feel justified to argue that relational integrativity as it is presented here is the only or the most important determinant of priming across all paradigms. Furthermore, the concept of integrativity might not be directly applicable to all implicit attitude procedures (e.g., when abstract stimuli are used as CSs and acquire their valence in an evaluative conditioning procedure), but a somewhat similar rationale could still apply. On a very general level, factors which facilitate joint encoding should strengthen the evaluative effects and factors which disrupt joint encoding should lead to weaker evaluative effects. Thus, granting that the various task settings allow two stimuli to be easily integrated (vs. not) into a meaningful compound, it could be the case that integrativity might play a role for other paradigms such as evaluative conditioning (De Houwer, Thomas, \& Baeyens, 2001) or the affect misattribution procedure (AMP; Payne, Cheng, Govorun, \& Stewart, 2005). For the time being, however, we showed that integrativity is indeed of great importance for evaluative priming.

Note that integrativity constitutes a more restrictive condition than valence congruity; faster responding on congruent trials is only observed for integrative pairs, not for non-integrative pairs. For facilitation to occur, congruent stimuli also have to be integrative. Moreover, the crucial condition for facilitation is further restricted by valence asymmetry. As visible from several analyses (Burghardt \& Unkelbach, 2014; Fiedler et al., 2011), but concealed in many other studies that did not report results across all $2 \times 2$ trial types, EP facilitation is regularly stronger for 
congruent-positive compared to congruent-negative trials. Taken together, this twofold restriction of EP to integrative and positive pairs may reflect the same critical factor, namely, the readiness to generate an integrative prime-target compound, which is neither determined by overlapping features in semantic memory (such as valence) nor by co-occurrence rate (Maki \& Buchanan, 2008). This generative potential was indeed shown in the pilot study to be systematically higher for positive than for negative stimulus pairs. This is also in line with the well-established findings of enhanced creative associations, the construction of broader categories (Isen \& Daubman, 1984), and the operation of top-down inferential processing (an assimilative processing mode, Fiedler, 2001) following positive situations or stimuli.

Such a propensity to generate compounds from positive stimuli is well in line with a growing body of evidence for the density model (Unkelbach et al., 2008), which implies shorter distances and more ramified connections between positive than negative stimuli. Further research may reveal, with respect to Maki and Buchanan's (2008) distinction of three largely independent measures of associations, that generative measures, rather than feature overlap or co-occurrence measures, are of most importance to the density model. Thus, the general finding that positive stimuli are more densely interconnected than negative ones does not appear to reflect stronger overlap of semantic features (as also noted by Estes \& Jones, 2009) nor does it appear to reflect ecological occurrence rates. More plausibly, though, it reflects the same generative potential to create original links and compounds that was also shown here to determine the emergence and strength of EP effects. However, since an asymmetric congruity effect emerged even when controlling for integrativity (Experiment 2), the positivity effects seem to be at least partially independent of integrativity.

The evidence presented here calls for a revised perspective on EP. The basic congruity effect, which was initially assumed to reflect a robust principle (Fazio, 2001; Klauer \& Musch, 2003), may actually not apply to all valence-congruent stimulus pairs. EP is an extreme version of categorical priming, based on the assumption that responses to all positive (vs. negative) targets will be facilitated after exposure to any positive (vs. negative) prime. Whereas previous EP research and theorizing did not explicitly reduce the domain of all stimuli sharing the same valence, it may not be too surprising that this assumption turns out to be unrealistic. Valence congruity is simply too broad and unrestricted a condition to render priming functional and informative. The present findings suggest that integrativity is a promising candidate for a more refined conception of valence congruity. When a prime and a target solicit the generation of a new compound, which goes beyond the old semantic attributes of the component stimuli, the vividly experienced valence of the compound seems to facilitate congruent evaluative reactions in target judgment tasks.

It could also be the case that reaction times were influenced by a response compatibility mechanism. Similar to the idea behind the affective matching model (Wentura, 2000) the stimulus pairs might have imposed a yes/no question to the participants (e.g. "is prime target?" or "is this plausible?"). A "yes" response to such a question might map onto a "positive" response while a "no" response to such a question might map onto a "negative" response. Assuming that the integrative word pairs lead to such a "yes" response and non-integrative pairs lead to a "no" response, there is a possibility for conflicts to occur as a function of target valence and integrativity. For integrative pairs, positive targets should lead to an increase in speed and negative targets to a decrease. For non-integrative pairs, positive targets should lead to a decrease in speed and negative targets to an increase. In other words, there should be a target valence $\times$ integrativity interaction. However, we did not find such an interaction in any of our three experiments.

An open question is whether the notion of integrativity can be extended to nonverbal (e.g., pictorial) stimuli or prime-target pairs presented in different modalities (e.g., picture-word pairs). Would, for instance, positive or negative facial expressions, or film clips, only facilitate the evaluation of congruent trait words if they are applicable (cf. Higgins, Rholes, \& Jones, 1977) to form an integrative impression? Would negative words trigger avoidance responses only when verbal primes are relevant to forming an avoidance compound (i.e., if the word valence qualifies the evaluative consequences of the stimulus person for the participant; cf. Wentura, Rothermund, \& Bak, 2000)? Furthermore, we presented stimuli in a way which is typical for priming experiments: Nouns served as primes and adjectives served as targets. This setup might facilitate a specific type of relational integration (e.g., concept-has-property) and it remains an open question whether integrativity effects would be similar for different setups.

If future research lends further support to the proposed generative version of priming, involving the creation of new compounds rather than the retrieval of stored semantic attributes, this process should plausibly take place in working memory rather than in semantic long-term memory (e.g., Ratcliff \& McKoon, 1988). However, whereas in the original compound-cue model the compound formation is dependent on the frequency of cooccurrence in texts and the strength of association at encoding, it is not necessarily the case within the present approach as integrative priming occurs for concepts which are not always associated or similar. Thus, the assumption of a universal, deterministic and inflexible process determined by long-term structures in the central or peripheral nervous system would have to be refined by a more flexible process that is subject to cognitive online activities and strategic exploitation of the stimulus context (Freytag, Bluemke, \& Fiedler, 2011; Klauer et al, 2009).

Author note The research reported in this article was supported by a Koselleck grant from the Deutsche Forschungsgemeinschaft awarded to Klaus Fiedler (Fi 294/23-1). 


\section{Appendix}

Table 1 German prime words (nouns) and target words (adjectives) used for material tests in Experiments 1 and 3

\begin{tabular}{|c|c|c|c|}
\hline \multicolumn{2}{|l|}{ German } & \multicolumn{2}{|l|}{ English } \\
\hline Primes & Targets & Primes & Targets \\
\hline \multicolumn{4}{|c|}{ Positive stimuli } \\
\hline Bett & angenehm & bed & Pleasant \\
\hline Buch & attraktiv & book & Attractive \\
\hline Diamant & beliebt & diamond & Popular \\
\hline Dusche & echt & shower & Genuine \\
\hline Eis & farbig & ice & Colored \\
\hline Garten & flexibel & garden & Flexible \\
\hline Herz & gemütlich & heart & Comfortable \\
\hline Kakao & hübsch & cocoa & Pretty \\
\hline Kamin & komisch & chimney & Comical \\
\hline Kerze & kuschelig & candle & Cuddly \\
\hline Küste & lustig & coast & Funny \\
\hline Medaille & natürlich & medal & Natural \\
\hline Milch & offen & milk & Open \\
\hline Natur & originell & nature & Fancy \\
\hline Oase & phantasievoll & oasis & Imaginative \\
\hline Obst & phantastisch & fruit & Fantastic \\
\hline Parfum & praktisch & perfume & Practical \\
\hline Photo & schön & photo & Beautiful \\
\hline Ring & toll & ring & Great \\
\hline Sessel & wertvoll & armchair & Precious \\
\hline \multicolumn{4}{|c|}{ Negative stimuli } \\
\hline Abfall & altmodisch & waste & Oldfashioned \\
\hline Bahre & bieder & bier & Respectable \\
\hline Benzin & blass & gasoline & Pale \\
\hline Blut & dick & blood & Corpulent \\
\hline Dolch & dreckig & dagger & Filthy \\
\hline Droge & düster & drug & Dark \\
\hline Falle & ekelhaft & trap & Disgustful \\
\hline Gas & eng & gas & Cramped \\
\hline Gift & erschreckend & poison & Scary \\
\hline Hagel & fett & hail & Fat \\
\hline Horde & grob & horde & Rude \\
\hline Keule & gruselig & club & Creepy \\
\hline Knebel & hässlich & knob & Ugly \\
\hline Leiche & langweilig & corpse & Boring \\
\hline Makel & laut & flaw & Loud \\
\hline Moder & öde & moldiness & Bleak \\
\hline Munition & schmutzig & ammunition & Dirty \\
\hline Rechnung & staubig & bill & Dusty \\
\hline Unrat & stumpf & refuse & Dull \\
\hline Urne & widerlich & urn & Disgusting \\
\hline
\end{tabular}

Table 2 Mean integrativity ratings of the stimulus pairs used in Experiments 1 and 3

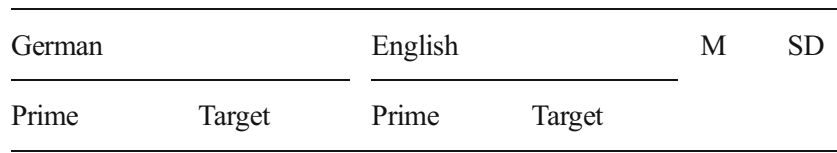

High Integrativity

Positive Prime/Positive Target

$\begin{array}{llllll}\text { Dusche } & \text { angenehm } & \text { shower } & \text { pleasant } & 21.00 & 0.00 \\ \text { Diamant } & \text { echt } & \text { diamond } & \text { genuine } & 21.00 & 0.00 \\ \text { Bett } & \text { gemütlich } & \text { bed } & \text { comfortable } & 20.60 & 1.26 \\ \text { Garten } & \text { schön } & \text { garden } & \text { beautiful } & 20.29 & 1.33 \\ \text { Parfum } & \text { attraktiv } & \text { perfume } & \text { attractive } & 20.22 & 1.99 \\ \text { Kerze } & \text { kuschelig } & \text { candle } & \text { cuddly } & 20.00 & 1.26 \\ \text { Eis } & \text { beliebt } & \text { ice } & \text { popular } & 19.00 & 3.23 \\ \text { Medaille } & \text { hübsch } & \text { medal } & \text { pretty } & 16.00 & 4.08 \\ & & & & \mathbf{1 9 . 7 6} & \mathbf{1 . 6 4}\end{array}$

Positive Prime/Negative Target

$\begin{array}{llllll}\text { Sessel } & \text { altmodisch } & \text { armchair } & \text { oldfashioned } & 19.83 & 1.17 \\ \text { Photo } & \text { hässlich } & \text { photo } & \text { ugly } & 19.50 & 2.81 \\ \text { Kamin } & \text { dreckig } & \text { chimney } & \text { dirty } & 19.00 & 2.59 \\ \text { Milch } & \text { fett } & \text { milk } & \text { fat } & 18.43 & 3.05 \\ \text { Buch } & \text { langweilig } & \text { book } & \text { boring } & 17.55 & 4.97 \\ \text { Natur } & \text { schmutzig } & \text { nature } & \text { dirty } & 15.69 & 5.15 \\ \text { Kakao } & \text { dick } & \text { cocoa } & \text { corpulent } & 15.50 & 6.36 \\ \text { Ring } & \text { bieder } & \text { ring } & \text { respectable } & 14.83 & 6.48 \\ & & & & \mathbf{1 7 . 5 4} & \mathbf{4 . 0 7}\end{array}$

Negative Prime/Positive Target

$\begin{array}{llllll}\text { Gas } & \text { natürlich } & \text { gas } & \text { natural } & 18.71 & 1.70 \\ \text { Leiche } & \text { echt } & \text { corpse } & \text { genuine } & 17.14 & 3.85 \\ \text { Droge } & \text { beliebt } & \text { drug } & \text { popular } & 17.00 & 5.48 \\ \text { Urne } & \text { wertvoll } & \text { urn } & \text { precious } & 16.10 & 5.63 \\ \text { Benzin } & \text { praktisch } & \text { gasoline } & \text { practical } & 16.09 & 3.78 \\ \text { Horde } & \text { lustig } & \text { horde } & \text { funny } & 16.00 & 5.06 \\ \text { Blut } & \text { farbig } & \text { blood } & \text { colored } & 15.00 & 4.08 \\ \text { Falle } & \text { phantasievoll } & \text { trap } & \text { imaginative } & 14.44 & 7.49 \\ & & & & \mathbf{1 6 . 3 1} & \mathbf{4 . 6 3}\end{array}$

Negative Prime/Negative Target

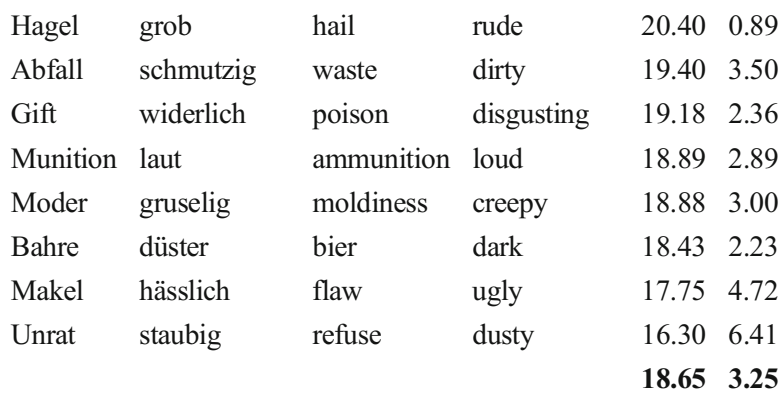

Low Integrativity

Positive Prime/Positive Target

$\begin{array}{llllll}\text { Kerze } & \text { lustig } & \text { candle } & \text { funny } & 1.4 & 1.7 \\ \text { Milch } & \text { phantasievoll } & \text { milk } & \text { imaginative } & 3.4 & 5.4 \\ \text { Ring } & \text { kuschelig } & \text { ring } & \text { cuddly } & 3.5 & 5.0\end{array}$


Table 2 (continued)

\begin{tabular}{|c|c|c|c|c|c|}
\hline \multicolumn{2}{|l|}{ German } & \multicolumn{2}{|l|}{ English } & \multirow[t]{2}{*}{$\mathrm{M}$} & \multirow[t]{2}{*}{$\mathrm{SD}$} \\
\hline Prime & Target & Prime & Target & & \\
\hline Obst & flexibel & fruit & flexible & 3.6 & 4.3 \\
\hline Kamin & komisch & chimney & comical & 4.0 & 5.8 \\
\hline Dusche & originell & shower & fancy & 4.8 & 5.1 \\
\hline Kakao & attraktiv & cocoa & attractive & 6.5 & 5.4 \\
\hline Parfum & gemütlich & perfume & comfortable & 6.9 & 4.9 \\
\hline & & & & 4.3 & 4.7 \\
\hline
\end{tabular}

Positive Prime/Negative Target

$\begin{array}{llllll}\text { Eis } & \text { altmodisch } & \text { ice } & \text { oldfashioned } & 0.0 & 0.0 \\ \text { Herz } & \text { dreckig } & \text { heart } & \text { filthy } & 1.5 & 3.1 \\ \text { Garten } & \text { widerlich } & \text { garden } & \text { disgusting } & 1.9 & 2.7 \\ \text { Buch } & \text { laut } & \text { book } & \text { loud } & 3.8 & 4.1 \\ \text { Küste } & \text { dick } & \text { coast } & \text { corpulent } & 4.3 & 6.0 \\ \text { Oase } & \text { hässlich } & \text { oasis } & \text { ugly } & 4.6 & 5.8 \\ \text { Bett } & \text { düster } & \text { bed } & \text { dark } & 4.8 & 5.4 \\ \text { Sessel } & \text { erschreckend } & \text { armchair } & \text { creepy } & 5.0 & 5.8 \\ & & & & \mathbf{3 . 2} & \mathbf{4 . 1}\end{array}$

Negative Prime/Positive Target

$\begin{array}{llllll}\text { Urne } & \text { kuschelig } & \text { urn } & \text { cuddly } & 0.0 & 0.0 \\ \text { Leiche } & \text { angenehm } & \text { corpse } & \text { pleasant } & 0.3 & 0.5 \\ \text { Blut } & \text { attraktiv } & \text { blood } & \text { attractive } & 1.0 & 1.7 \\ \text { Dolch } & \text { gemütlich } & \text { dagger } & \text { comfortable } & 2.1 & 3.2 \\ \text { Falle } & \text { hübsch } & \text { trap } & \text { pretty } & 3.6 & 6.1 \\ \text { Knebel } & \text { phantastisch } & \text { knob } & \text { fantastic } & 4.2 & 3.7 \\ \text { Makel } & \text { offen } & \text { flaw } & \text { open } & 5.3 & 7.1 \\ \text { Horde } & \text { praktisch } & \text { horde } & \text { practical } & 6.5 & 5.6 \\ & & & & \mathbf{2 . 9} & \mathbf{3 . 5}\end{array}$

Negative Prime/Negative Target

\begin{tabular}{llllll} 
Unrat & fett & refuse & fat & 3.2 & 0.8 \\
Hagel & bieder & hail & respectable & 3.5 & 5.3 \\
Keule & eng & club & cramped & 3.8 & 4.5 \\
Bahre & laut & bier & loud & 4.2 & 6.1 \\
Gas & staubig & gas & dusty & 4.2 & 4.3 \\
Munition & öde & ammunition & bleak & 4.5 & 3.7 \\
Gift & grob & poison & rude & 5.3 & 4.9 \\
Benzin & stumpf & gasoline & dull & 5.5 & 5.5 \\
& & & & $\mathbf{4 . 3}$ & $\mathbf{4 . 4}$ \\
\hline
\end{tabular}

Table 3 German prime words (nouns) and target words (adjectives) used for material tests in Experiment 2

\begin{tabular}{|c|c|c|c|}
\hline \multicolumn{2}{|l|}{ German } & \multicolumn{2}{|l|}{ English } \\
\hline Primes & Targets & Primes & Targets \\
\hline \multicolumn{4}{|c|}{ Positive stimuli } \\
\hline Apfel & fair & apple & fair \\
\hline Bild & freundlich & picture & friendly \\
\hline Blick & fröhlich & view & cheerful \\
\hline Blüte & gesund & bloom & healthy \\
\hline Buch & glücklich & book & happy \\
\hline Duft & herzlich & scent & cordial \\
\hline Erdbeere & kreativ & strawberry & creative \\
\hline Erde & lieb & earth & dear \\
\hline Geschenk & lustig & present & funny \\
\hline Getränk & natürlich & drink & natural \\
\hline Kind & phantasievoll & child & imaginative \\
\hline Kuss & sanft & kiss & gentle \\
\hline Meer & schön & sea & beautiful \\
\hline Strand & warm & beach & warm \\
\hline Wald & witzig & forest & comical \\
\hline Wiese & zart & meadow & delicate \\
\hline Wohnung & zufrieden & apartment & content \\
\hline \multicolumn{4}{|c|}{ Negative stimuli } \\
\hline Abfall & arrogant & waste & arrogant \\
\hline Bettler & blöde & beggar & stupid \\
\hline Blut & bösartig & blood & vicious \\
\hline Fabrik & brutal & factory & brutal \\
\hline Gefängnis & destruktiv & prison & destructive \\
\hline Gift & grob & poison & rude \\
\hline Gitter & heimtückisch & bar & insidious \\
\hline Grab & kaputt & grave & broken \\
\hline Kosten & miserabel & costs & miserable \\
\hline Lawine & monoton & avalanche & monotonous \\
\hline Leiche & neidisch & corpse & envious \\
\hline Räuber & peinlich & robber & embarrassing \\
\hline Revolver & scheinheilig & revolver & sanctimonious \\
\hline Schmutz & streng & dust & strict \\
\hline Schleim & tödlich & slime & deadly \\
\hline Staub & ungerecht & dirt & unjust \\
\hline Sumpf & verwundet & morass & injured \\
\hline
\end{tabular}


Table 4 Mean integrativity ratings of the stimulus pairs used in Experiment 2

\begin{tabular}{|c|c|c|c|c|c|}
\hline \multicolumn{2}{|c|}{ German } & \multicolumn{2}{|c|}{ English } & \multirow[t]{2}{*}{ M } & \multirow[t]{2}{*}{ SD } \\
\hline Prime & Target & Prime & Target & & \\
\hline
\end{tabular}

High Integrativity

Positive Prime/Positive Target

$\begin{array}{llllll}\text { Wald } & \text { natürlich } & \text { forest } & \text { natural } & 20.29 & 1.11 \\ \text { Wald } & \text { gesund } & \text { forest } & \text { healthy } & 19.50 & 2.35 \\ \text { Wiese } & \text { warm } & \text { meadow } & \text { warm } & 18.83 & 2.40 \\ \text { Getränk } & \text { warm } & \text { drink } & \text { warm } & 18.60 & 4.99 \\ \text { Geschenk } & \text { witzig } & \text { present } & \text { comical } & 16.00 & 8.09 \\ \text { Bild } & \text { witzig } & \text { picture } & \text { comical } & 15.89 & 3.69 \\ \text { Blüte } & \text { gesund } & \text { bloom } & \text { healthy } & 13.83 & 7.68 \\ \text { Kind } & \text { sanft } & \text { child } & \text { gentle } & 12.43 & 6.80 \\ & & & & \mathbf{1 6 . 9 2} & \mathbf{4 . 6 4}\end{array}$

Positive Prime/Negative Target

$\begin{array}{llllll}\text { Kind } & \text { bösartig } & \text { child } & \text { vicious } & 19.20 & 1.79 \\ \text { Getränk } & \text { tödlich } & \text { drink } & \text { dealdy } & 19.20 & 1.79 \\ \text { Kind } & \text { neidisch } & \text { child } & \text { envious } & 18.50 & 3.70 \\ \text { Bild } & \text { peinlich } & \text { picture } & \text { embarrassing } & 16.63 & 5.73 \\ \text { Apfel } & \text { tödlich } & \text { apple } & \text { deadly } & 16.11 & 6.43 \\ \text { Duft } & \text { streng } & \text { scent } & \text { strict } & 15.29 & 6.55 \\ \text { Meer } & \text { heimtückisch } & \text { sea } & \text { insidious } & 15.14 & 6.28 \\ \text { Wald } & \text { kaputt } & \text { forest } & \text { broken } & 14.80 & 6.65 \\ & & & & \mathbf{1 6 . 8 6} & \mathbf{4 . 8 6}\end{array}$

Negative Prime/Positive Target

$\begin{array}{llllll}\text { Lawine } & \text { natürlich } & \text { avalanche } & \text { natural } & 16.92 & 3.50 \\ \text { Staub } & \text { natürlich } & \text { dust } & \text { natural } & 16.60 & 6.70 \\ \text { Blut } & \text { warm } & \text { blood } & \text { warm } & 15.57 & 7.52 \\ \text { Blut } & \text { gesund } & \text { blood } & \text { healthy } & 15.57 & 5.74 \\ \text { Sumpf } & \text { warm } & \text { morass } & \text { warm } & 14.00 & 5.55 \\ \text { Kosten } & \text { fair } & \text { costs } & \text { fair } & 13.40 & 8.26 \\ \text { Bettler } & \text { freundlich } & \text { beggar } & \text { friendly } & 13.20 & 5.01 \\ \text { Räuber } & \text { phantasievoll } & \text { robber } & \text { imaginative } & 13.11 & 7.25 \\ & & & & \mathbf{1 4 . 8 0} & \mathbf{6 . 1 9}\end{array}$

Negative Prime/Negative Target

$\begin{array}{llllll}\text { Fabrik } & \text { monoton } & \text { factory } & \text { monotonous } & 19.14 & 3.29 \\ \text { Lawine } & \text { destruktiv } & \text { avalanche } & \text { destructive } & 17.57 & 7.35 \\ \text { Blut } & \text { verwundet } & \text { blood } & \text { injured } & 17.00 & 6.09 \\ \text { Gefängnis } & \text { streng } & \text { prison } & \text { strict } & 16.22 & 8.18 \\ \text { Gitter } & \text { monoton } & \text { bar } & \text { monotonous } & 14.57 & 8.75 \\ \text { Leiche } & \text { brutal } & \text { corpse } & \text { brutal } & 13.79 & 8.66 \\ \text { Revolver } & \text { destruktiv } & \text { revolver } & \text { destructive } & 12.60 & 11.50 \\ \text { Gefängnis } & \text { miserabel } & \text { prison } & \text { miserable } & 10.71 & 10.06 \\ & & & & \mathbf{1 5 . 2 0} & \mathbf{7 . 9 9} \\ \end{array}$

Table 5 Mean integrativity ratings of the stimulus pairs used in Study 2

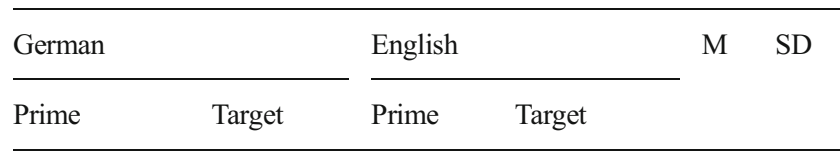

Low Integrativity

Positive Prime/Positive Target

$\begin{array}{llllll}\text { Strand } & \text { fair } & \text { beach } & \text { fair } & 3.40 & 3.92 \\ \text { Getränk } & \text { lieb } & \text { drink } & \text { dear } & 4.89 & 4.54 \\ \text { Apfel } & \text { kreativ } & \text { apple } & \text { creative } & 5.75 & 3.77 \\ \text { Erdbeere } & \text { kreativ } & \text { strawberry } & \text { creative } & 6.33 & 5.24 \\ \text { Getränk } & \text { zart } & \text { drink } & \text { delicate } & 7.11 & 6.19 \\ \text { Buch } & \text { zart } & \text { book } & \text { delicate } & 7.14 & 4.60 \\ \text { Apfel } & \text { fair } & \text { apple } & \text { fair } & 9.50 & 9.27 \\ \text { Meer } & \text { witzig } & \text { sea } & \text { comical } & 9.71 & 7.06 \\ & & & & \mathbf{6 . 7 3} & \mathbf{5 . 5 8}\end{array}$

Positive Prime/Negative Target

\begin{tabular}{|c|c|c|c|c|}
\hline Wohnung & bösartig & apartment & vicious & 3.83 \\
\hline Apfel & destruktiv & apple & destructive & 3.86 \\
\hline Wiese & scheinheilig & meadow & sanctimonious & 4.38 \\
\hline Kuss & kaputt & kiss & broken & 4.63 \\
\hline Meer & blöde & sea & stupid & 4.69 \\
\hline Duft & kaputt & scent & broken & 5.86 \\
\hline Buch & neidisch & book & envious & 6.83 \\
\hline Wohnung & brutal & apartment & brutal & 6.88 \\
\hline
\end{tabular}

Negative Prime/Positive Target

$\begin{array}{llllll}\text { Gefängnis } & \text { fröhlich } & \text { prison } & \text { cheerful } & 1.20 & 2.17 \\ \text { Räuber } & \text { lieb } & \text { robber } & \text { dear } & 3.67 & 3.14 \\ \text { Lawine } & \text { kreativ } & \text { avalanche } & \text { creative } & 3.86 & 7.69 \\ \text { Sumpf } & \text { lustig } & \text { morass } & \text { funny } & 4.86 & 5.61 \\ \text { Revolver } & \text { witzig } & \text { revolver } & \text { comical } & 4.86 & 4.98 \\ \text { Revolver } & \text { natürlich } & \text { revolver } & \text { natural } & 5.00 & 4.90 \\ \text { Leiche } & \text { zart } & \text { corpse } & \text { delicate } & 5.89 & 5.04 \\ \text { Schmutz } & \text { gesund } & \text { dirt } & \text { healthy } & 6.00 & 7.28 \\ & & & & \mathbf{4 . 4 2} & \mathbf{5 . 1 0}\end{array}$

Negative Prime/Negative Target

\begin{tabular}{llllll} 
Kosten & verwundet & costs & injured & 2.20 & 1.92 \\
Fabrik & peinlich & factory & embarrassing & 2.33 & 2.78 \\
Staub & scheinheilig & dust & sanctimonious & 2.88 & 3.18 \\
Sumpf & arrogant & morass & arrogant & 4.00 & 7.68 \\
Grab & neidisch & grave & envious & 4.10 & 4.77 \\
Staub & neidisch & dust & envious & 4.63 & 5.78 \\
Lawine & peinlich & avalanche & embarrassing & 5.20 & 7.92 \\
Blut & arrogant & blood & arrogant & 9.50 & 10.47 \\
& & & & $\mathbf{4 . 3 5}$ & $\mathbf{5 . 5 6}$ \\
\hline
\end{tabular}




\section{References}

Alexopoulos, T., Fiedler, K., \& Freytag, P. (2012). The impact of open and closed mindsets on evaluative priming. Cognition and Emotion, 26, 978-994.

Anderson, J. R., \& Bower, G. H. (1973). Human associative memory. Washington, DC: V.H. Winston.

Brunswik, E. (1952). The conceptual framework of psychology. (Int. Encycl. unified Sci., 1(10), ). Oxford England: Univ. Chicago Press.

Burghardt, J., \& Unkelbach, C. (2014). A meta-analysis of sequential affective and evaluative priming: Effects, theories, and recommendations for applications. Manuscript submitted for publication.

Chan, E., Ybarra, O., \& Schwarz, N. (2006). Reversing the affective congruency effect: The role of target word frequency of occurrence. Journal of Experimental Social Psychology, 42, 365-372.

Clark, H. H. (1973). The language-as-fixed-effect fallacy: A critique of language statistics in psychological research. Journal of Verbal Learning and Verbal Behavior, 12(4), 335-359.

De Houwer, J., Hermans, D., \& Eelen, P. (1998). Affective and identity priming with episodically associated stimuli. Cognition and Emotion, 12, 145-169.

De Houwer, J., Thomas, S., \& Baeyens, F. (2001). Associative learning of likes and dislikes: A review of 25 years of research on human evaluative conditioning. Psychological Bulletin, 127, 853-869.

Estes, Z., \& Jones, L. L. (2009). Integrative priming occurs rapidly and uncontrollably during lexical processing. Journal of Experimental Psychology: General, 138, 112-130.

Fazio, R. H. (2001). On the automatic activation of associated evaluations: An overview. Cognition and Emotion, 15, 115-141.

Fazio, R. H., Sanbonmatsu, D. M., Powell, M. C., \& Kardes, F. R. (1986). On the automatic activation of attitudes. Journal of Personality and Social Psychology, 50, 229-238.

Fiedler, K. (2001). Affective influences on social information processing. In J. P. Forgas (Ed.), Handbook of affect and social cognition (pp. 163-185). New Jersey: Lawrence Erlbaum Associates.

Fiedler, K., Bluemke, M., \& Unkelbach, C. (2011). On the adaptive flexibility of evaluative priming. Memory and Cognition, 39, $557-$ 572.

Fiedler, K., \& Hütter, M. (2013). Memory and Emotion. In T. Perfect \& S. Lindsay (Eds.), Handbook of Applied Memory. London: Sage Publications.

Fiedler, K., Nickel, S., Asbeck, J., \& Pagel, U. (2003). Mood and the generation effect. Cognition and Emotion, 17, 585-608.

Fockenberg, D. A., Koole, S. L., \& Semin, G. R. (2008). Priming in concert: Assimilation and contrast with multiple affective and gender primes. Social Cognition, 26(6), 647-669.

Freytag, P., Bluemke, M., \& Fiedler, K. (2011). An adaptive-learning approach to affect regulation: Strategic influences on evaluative priming. Cognition and Emotion, 25, 426-439.

Gagné, C. L. (2000). Relation-based combinations versus property-based combinations: A test of the CARIN theory and the dual-process theory of conceptual combination. Journal Of Memory And Language, 42, 365-389.

Glaser, J., \& Banaji, M. R. (1999). When fair is foul and foul is fair: Reverse priming in automatic evaluation. Journal of Personality and Social Psychology, 77, 669-687.

Hager, W., Mecklenbräuker, S., Möller, H., \& Westermann, R. (1985). Emotionsgehalt, Bildhaftigkeit, Konkretheit und Bedeutungshaltigkeit von 580 Adjektiven: Ein Beitrag zur Normierung und zur Prüfung einiger Zusammenhangshypothesen. Archiv für Psychologie, 137, 75-97.

Hermans, D., De Houwer, J., \& Eelen, P. (2001). A time course analysis of the affective priming effect. Cognition \& Emotion, 15(2), 143165
Hermans, D., Houwer, J. D., \& Eelen, P. (1994). The affective priming effect: Automatic activation of evaluative information in memory. Cognition \& Emotion, 8(6), 515-533.

Hermans, D., Spruyt, A., \& Eelen, P. (2003). Automatic affective priming of recently acquired stimulus valence: Priming at SOA 300 but not at SOA 1000. Cognition and Emotion, 17, 83-99.

Hermans, D., Van den Broeck, A., \& Eelen, P. (1998). Affective priming using a color naming task: A test of an affective-motivational account of affective priming effects. Zeitschrift für Experimentelle Psychologie, 45, 136-148.

Herring, D. R., White, K. R., Jabeen, L. N., Hinojos, M., Terrazas, G., Reyes, S. M., \& ... Crites, S. R. (2013). On the automatic activation of attitudes: A quarter century of evaluative priming research. Psychological Bulletin, 139(5), 1062-1089.

Higgins, E. T., Rholes, W. S., \& Jones, C. R. (1977). Category accessibility and impression formation. Journal of Experimental Social Psychology, 13(2), 141-154.

Isen, A. M., \& Daubman, K. A. (1984). The influence of affect on categorization. Journal of Personality and Social Psychology, 47, 12061217.

Jones, L. L., \& Golonka, S. (2012). Different influences on lexical priming for integrative, thematic, and taxonomic relations. Frontiers In Human Neuroscience, 6.

Klauer, K. C., \& Musch, J. (2003). Affective priming: Findings and theories. In J. Musch \& K. C. Klauer (Eds.), The psychology of evaluation: Affective processes in cognition and emotion (pp. 7 49). Mahwah: Erlbaum.

Klauer, K. C., Musch, J., \& Eder, A. B. (2005). Priming of semantic classifications: Late and response related, or earlier and more central?.Psychonomic. Bulletin \& Review, 12(5), 897-903.

Klauer, K. C., Roßnagel, C., \& Musch, J. (1997). List-context effects in evaluative priming. Journal of Experimental Psychology: Learning, Memory, and Cognition, 23, 246-255.

Klauer, K. C., \& Stern, E. (1992). How attitudes guide memory-based judgments: A two-process model. Journal of Experimental Social Psychology, 28, 186-206.

Klauer, K. C., Teige-Mocigemba, S., \& Spruyt, A. (2009). Contrast effects in spontaneous evaluations. Journal of Personality and Social Psychology, 96, 265-287.

Klinger, M. R., Burton, P. C., \& Pitts, G. S. (2000). Mechanisms of unconscious priming: I. Response competition, not spreading activation. Journal of Experimental Psychology: Learning, Memory, and Cognition, 26, 441-455.

Kohler, I. (1962). Experiments with goggles. Scientific American, 206, $62-86$.

Maki, W. S., \& Buchanan, E. (2008). Latent structure in measures of associative, semantic, and thematic knowledge. Psychonomic Bulletin and Review, 15, 598-603.

Mather, E., Jones, L. L., \& Estes, Z. (2014). Priming by relational integration in perceptual identification and Stroop colour naming. Journal of Memory and Language, 71(1), 57-70.

Möller, H., \& Hager, W. (1991). Angenehmheit, Bedeutungshaltigkeit, Bildhaftigkeit und Konkretheit-Abstraktheit von 452 Adjektiven [Pleasantness, meaningfulness, imageability and concreteness of 452 adjectives]. Sprache und Kognition, 10, 39-51.

Musch, J., \& Klauer, K. C. (2001). Locational uncertainty moderates affective congruency effects in the evaluative decision task. Cognition \& Emotion, 15(2), 167-188.

Osgood, C. E., Suci, G., \& Tannenbaum, P. (1957). The measurement of meaning. Urbana: University of Illinois Press.

Payne, B. K., Cheng, C. M., Govorun, O., \& Stewart, B. D. (2005). An inkblot for attitudes: Affect misattribution as implicit measurement. Journal of Personality and Social Psychology, 89, 277-293.

Ratcliff, R., \& McKoon, G. (1988). A retrieval theory of priming in memory. Psychological Review, 95, 385-408. 
Rosenthal, R., \& Rosnow, R. L. (1985). Contrast analysis: Focused comparisons in the analysis of variance. Cambridge University Press.

Rozin, P., Berman, L., \& Royzman, E. (2010). Biases in use of positive and negative words across twenty natural languages. Cognition and Emotion, 24(3), 536-548.

Scherer, L. D., \& Lambert, A. J. (2009). Contrast effects in priming paradigms: Implications for theory and research on implicit attitudes. Journal of Personality and Social Psychology, 97, 383-403.

Schwibbe, M., Räder, K., Schwibbe, M., \& Geiken-Pophanken, G. (1981). Zum emotionalen Gehalt von Substantiven, Adjektiven und Verben. Zeitschrift für Experimentelle und Angewandte Psychologie, 28, 486-501.

Spruyt, A., De Houwer, J., Hermans, D., \& Eelen, P. (2007a). Affective priming of nonaffective semantic categorization responses. Experimental Psychology, 54, 44-53.

Spruyt, A., De Houwer, J., \& Hermans, D. (2009). Modulation of automatic semantic priming by feature-specific attention allocation. Journal of Memory and Language, 61(1), 37-54.

Spruyt, A., Hermans, D., De Houwer, J., Vandromme, H., \& Eelen, P. (2007b). On the nature of the affective priming effect: Effects of stimulus onset asynchrony and congruency proportion in naming and evaluative categorization. Memory and Cognition, 35, 95-106.

Storbeck, J., \& Clore, G. L. (2008). The affective regulation of cognitive priming. Emotion, 8, 208-215.
Unkelbach, C., Fiedler, K., Bayer, M., Stegmüller, M., \& Danner, D. (2008). Why positive information is processed faster: The density hypothesis. Journal of Personality and Social Psychology, 95, 3649.

Võ, M. L., Jacobs, A. M., \& Conrad, M. (2006). Cross-validating the Berlin affective word list. Behavior Research Methods, 38, 606609.

Wentura, D. (1999). Activation and inhibition of affective information: Evidence for negative priming in the evaluation task. Cognition and Emotion, 13, 65-91.

Wentura, D. (2000). Dissociative affective and associative priming effects in the lexical decision task: Yes versus no responses to word targets reveal evaluative judgment tendencies. Journal of Experimental Psychology: Learning, Memory, and Cognition, 26, 456-469.

Wentura, D. \& Degner, J. (2010). Practical guide to sequential priming and related tasks. In B. Gawronski \& B. K. Payne (Eds.), Handbook of Implicit Social Cognition: Measurement, Theory, and Applications (Chapter 6).

Wentura, D., Rothermund, K., \& Bak, P. (2000). Automatic vigilance: the attention-grabbing power of approach-and avoidance-related social information. Journal of Personality and Social Psychology, 78(6), 1024.

Wittenbrink, B., \& Schwarz, N. (Eds.). (2007). Implicit measures of attitudes. New York: Guilford Press. 